\title{
Prática docente em Trabalho \& Educação no Instituto Politécnico da UFRJ: relato de experiência em atividades educacionais.
}

Teaching practice in work and education at the Polytechnic Institute of UFRJ: the experience with educational activities.

\author{
Rodrigo Erdmann Oliveira ${ }^{1}$
}

Artigo recebido para publicação em jan./2015 e aceito para publicação em jun./2015

\section{RESUMO}

Este trabalho expõe as bases teóricas e institucionais do Instituto Politécnico da UFRJ em Cabo Frio - RJ, Escola Técnica de Ensino Médio e Projeto de Extensão, modelo experimental de educação pelo trabalho, que toma o trabalho como princípio educativo e a politecnia como método de formação humana na integração do trabalho analítico com o prático. Apresenta-se um relato da experiência na pedagogia por projetos, bem como algumas vertentes integradoras da proposta de educação científica da escola. A contribuição do artigo é sua análise do trabalho dentro das estratégias empreendidas para sua execução, bem como a divulgação da experiência como forma de transformação social. $\mathrm{O}$ artigo é um relato de uma experiência e uma autocrítica que busca ratificar ou complementar as propostas institucionais do Instituto Politécnico da UFRJ em Cabo Frio - RJ.

Palavras-chave: Trabalho \& Educação; Educação Científica; Atividades Pedagógicas.

\begin{abstract}
This paper presents the theoretical and institutional bases of the UFRJ Polytechnic Institute located in Cabo Frio, Rio de Janeiro, a Technical High School and Extension-Program Project, and known as an experimental model of education through work, which uses the work as an educational principle and the polytechnic as a human development method with the integration of analytical and practical work. It presents a report of the experience in project-based pedagogy, as well as some concepts of the school science education proposal. The contribution of this paper is the analysis of the undertaken work within the strategies for its implementation, as well as the dissemination of the experience as a way of social development. The article is a report of an experience and self-criticism which seeks to ratify or supplement the institutional proposals of the UFRJ Polytechnic Institute.
\end{abstract}

Keywords: Work \& Education; Science Education; Educational Activities.

\section{INTRODUÇÃO}

O Instituto Politécnico - IP, unidade Cabo Frio da UFRJ, remonta a experiências advindas principalmente do professor Fernando Amorim, quando então professor do curso de Engenharia Naval na Escola de Engenharia Politécnica da UFRJ e seus desafios inerentes à formação do engenheiro numa Universidade Pública. Estes mesmos desafios de formação relatados à época dos anos 1990 no

\footnotetext{
${ }^{1}$ Graduado em Engenharia Ambiental pela Universidade do Estado do Pará - UEPA, residente docente do curso de Formação e Qualificação em Residência Docente do IPUFRJ, UFRJ. E-mail: rodrigoerdmann@gmail.com
} 
ciclo básico de Engenharia (AMORIM, 2002), ainda hoje podem ser encontradas nas demais graduações. Ciclos básicos de formação desatrelados das matérias especificas e profissionalizantes das grades curriculares, nas quais professores de institutos alheios à graduação em questão ministram suas disciplinas sem compreenderem a problemática de reprovação e desistências do ciclo básico.

Infelizmente este quadro ainda se repete, em termos de ensino, de modo geral nas graduações em Engenharia, principalmente quando se chega ao último período e se percebem disciplinas profissionais que poderiam ter sido introduzidas antes para propiciar uma compreensão totalizante dos desafios enfrentados pelo aluno desde o início.

O professor Fernando Amorim, nesses idos da década de 1990 (AMORIM, 2002), assumiu o desafio de ministrar a disciplina Introdução a Engenharia Naval durante o primeiro e segundo períodos do curso, no intuito de diagnosticar o que se passava diante de tantas retenções e reprovações, além do pouco aproveitamento em termos quantitativos dos que conseguiam chegar ao fim da graduação e se formarem.

Pretende-se, portanto, com este trabalho expor um relato de experiência no IP da UFRJ no intuito de apresentar dados qualitativos desta experiência de formação politécnica como possível abordagem de Educação Profissional Integrada ao Ensino Médio que precisa atualizar-se diante os desafios postos pelo mundo do trabalho a despeito da quantidade expressiva de evasão no ensino médio (RODRIGUES et al, 2014).

\section{RESGATE HISTÓRICO}

A história dessa experiência remonta a redemocratização do Brasil e da UFRJ em 1985, quando das experiências de Extensão Universitária fomentadas politicamente pela reitoria da Universidade. Iniciativas interdisciplinares e integradas entre diversas áreas de conhecimento, como nos Projetos do Complexo da Maré, foram fundamentais para reunir e formar pesquisadores, professores, técnicos e estudantes entre a Faculdade de Letras e a Escola Politécnica do Centro de Tecnologia. 
Revista Tecnologia e Sociedade, Curitiba, v. 11, n. 22, 2015

Edição Especial XII Encontro Nacional de Engenharia e Desenvolvimento Social

ISSN (versão online): 1984-3526

ISSN (versão impressa): 1809-0044

Desde então, o debate acerca de propostas metodológicas de ensinoaprendizagem, tendo como premissas a prática, conceito e reflexão, já se gestavam para os envolvidos nestes projetos, que tinham como principais problemas o enfrentamento à resistência de setores da Universidade, os equívocos metodológicos, a falta de subsídios financeiros e a dificuldade de romper com o conhecimento disciplinar (VENTIN, 2014).

Infelizmente por conta de aspectos recorrentes de fragilidade institucional e conjunturas nacionais desfavoráveis, estes projetos não progrediram, mas tornaramse sementes para a discussão da formação educacional e qualificação profissional de jovens, bem como o debate de modelos educacionais para dentro e para fora da Universidade, tais quais as experiências na Engenharia Naval, no tópico acima mencionado.

Já no início dos anos 2000, com o alinhamento do governo de CentroEsquerda no Brasil, novamente iniciativas de extensão revigoraram na UFRJ, de modo interdisciplinar, mas neste caso, no Centro de Tecnologia. Com o objetivo de integração institucional e interiorização da Universidade, o grupo "UFRJ Mar", no ano de 2002, ligado a Engenharia Naval, congregou diversas iniciativas das Ciências do Mar com a coordenação do professor Fernando Amorim. A segunda edição do Festival em Arraial do Cabo - RJ, em 2003, contou com 3.000 pessoas atendidas em 26 oficinas, que contaram com a participação de 100 professores, técnicos e alunos de graduação e pós-graduação da UFRJ (VENTIN, 2014, p.48).

Nesse sentido, as primeiras ações foram os "Festivais UFRJ Mar", feiras de ciência e extensão científica em vários municípios litorâneos do Rio de Janeiro, oferecendo oficinas e tendo como público alvo estudantes de escolas públicas da região, o que ocasionou articulações políticas com as Prefeituras. Daí surge a parceria com o Município de Macaé através da Secretaria Municipal de Educação em 2003, para formação e qualificação de jovens de ensino fundamental no fortalecimento da pesca artesanal por meio da Escola Municipal de Pescadores de Macaé - EMPM. Ressalte-se que a pesca artesanal apresentava-se em crise nessa cidade por conta dos impactos de grande exploração petrolífera da região.

Infelizmente, as fragilidades institucionais no relacionamento com a Prefeitura Municipal de Macaé não permitiram que fosse adiante politicamente a experiência que se gestava num crescente aprendizado de um modelo educacional articulando 
prática e teoria, devido a falta de pagamento das bolsas dos docentes. Por outro lado, a Universidade também não sustentou o compromisso com o desenvolvimento de outros níveis de Educação, que não a Superior (VENTIN, 2014). No entanto, a experiência mostrava que o modelo de educação tenderia a ser integrado, ou seja, sem a segregação entre curso profissionalizante e ensino propedêutico, que era o que ocorria na EMPM, sendo a UFRJ responsável pelo turno profissionalizante e a Prefeitura de Macaé pelo ensino básico.

Entre os diversos aprendizados, o debate aproximava-se de diversas categorias educacionais, teórica e praticamente, seja através da formação de professores, seja através da política educacional vigente no país e o debate teórico para um modelo crítico-reflexivo da formação dos jovens.

Em 2008, depois da ocorrência de três eventos do Festival "UFRJ Mar" em Cabo Frio, numa negociação com a Secretaria de Educação desse município, que se interessou na qualificação profissional na área de meio ambiente e na presença da UFRJ no município, outra proposta de escola surge. Não mais como escola de pescadores, mas para formação no ensino fundamental e médio técnico, com a liberdade metodológica necessária e, diga-se de passagem, experimental de um Projeto de Extensão. Entenda-se aqui que experimental significa mesmo um laboratório de aprendizado, estudo e formação com as bases metodológicas que já se estava trabalhando. Nasce assim o primeiro Instituto Politécnico da UFRJ em Cabo Frio.

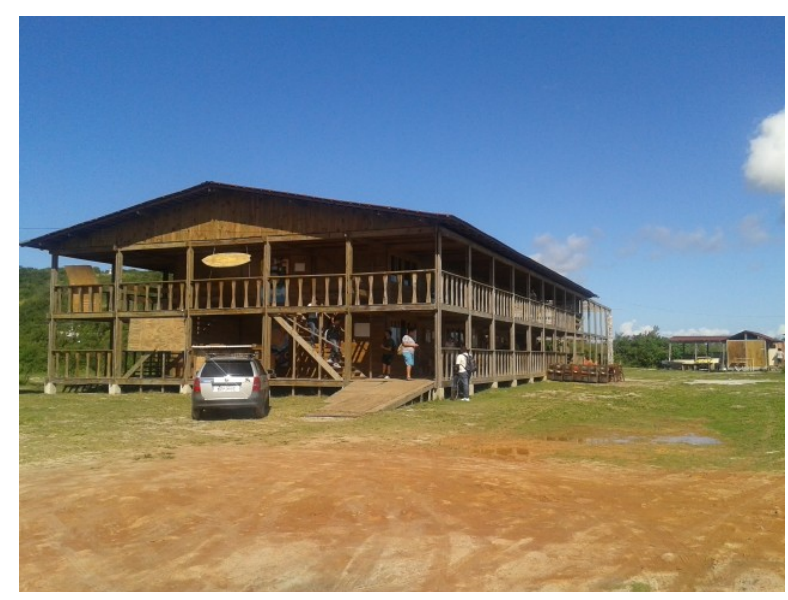

Figura 1: Foto das instalações modulares do IPUFRJ, 2014. Fonte: Imagens próprias. 
O IP ampara-se metodologicamente em uma série de categorias, tais quais a politecnia e educação integral, mas o debate fundamental da educação integral aconteceu e ainda acontece politicamente no Brasil por vias teóricas e através da própria militância de professores, pesquisadores, entidades e sindicatos, etc., que defendem um modelo educacional público. As conquistas podem ser poucas, mas já há um terreno fértil para experiências concorrentes aos modelos convencionais do Ensino Médio. Abaixo segue um pouco do trajeto institucional e legal percorrido.

A história recente, a partir da constituinte de 1988, mostra-nos certo conflito em relação às disputas legais referentes ao Ensino Médio e ao Ensino Profissionalizante no Brasil na gênese da Lei de Diretrizes e Bases da Educação (9.394/96) e adiante na revogação e manutenção de decretos afirmativos da LDB.

As principais discussões dizem respeito à política de finalidade e objetivos do Ensino Médio brasileiro: assim alimentou-se a perspectiva dual de ensino médio focado em formação geral, ou ensino médio para formação específica, as quais vão percorrer o debate geral desde a formulação da LDB de 1996.

Enquanto a LDB indicava possibilidades de formação profissional integrada à formação geral nos seus múltiplos aspectos humanísticos e científicos tecnológicos, o Decreto num. 2.208/97 veio a conformar essas duas propostas da LDB, no entanto, de modo a separar a educação geral da educação profissional em currículos e matrículas diferentes de acordo com os turnos diários de ensino. Desse modo, deslocou a formação profissional do ensino propedêutico no intuito de preparar o estudante para o mercado de trabalho a tornar-se mão de obra qualificada, ou seja, a educação de caráter público foi assim concebida para o setor privado. A partir deste decreto pode-se dizer que houve uma reforma pelo governo do ensino através do Programa de Expansão da Educação Profissional - PROEP, em 1997, e financiamento do Banco Interamericano de Desenvolvimento - BID, em atendimento a cartilha da política neoliberal, segundo Moura et al. (2007, p. 19).

Desde 1991 com base nos debates sobre a formulação da LDB da educação já se discutia a formação Politécnica como metodologia de educação integral, sem, no entanto, força política para as disputas e conquistas institucionais e legais. Somente em 2003, com um novo governo e a criação de canais para retomada de discussões das finalidades do Ensino Médio, o modelo então vigente começa a ser questionado. 
Será, portanto, através de mais uma força de Decreto, discutido com uma parcela da sociedade, que se avançará neste quesito. Após a revogação do restritivo Decreto 2.208/97, a criação do Decreto 5.124/2004 irá equacionar e complementar entre todos os interesses vigentes, a criação e legitimação da modalidade de Educação Integral articulada ao Ensino Médio, onde hoje se localiza o IPUFRJ. Seu objetivo seria de diminuir as discrepâncias da formação profissional com finalidade somente para o mercado de trabalho, ao mesmo tempo, consolidar a proposta de currículo integrado do artigo 39 LDB com vistas ao "trabalho, educação e tecnologia, conduzindo a aptidões para a vida produtiva" (MOURA et al., 2007).

Como nos diz Frigotto et al. (2006, p. 34), este momento de aprovação por decreto pode não ser tão vitorioso para a proposta, mas dentro das contradições do governo vigente a época, trouxe alguma resposta e oxigenação para a mobilização social na construção de algo mais sólido futuramente. A atual situação da legitimação de uma educação integradora dos conhecimentos gerais e específicos, portanto, está baseada em decreto, e não objetivamente na LDB da Educação, o que nos traz uma fragilidade a médio e longo prazo.

\section{BASES TEÓRICO-METODOLÓGICAS DO IPUFRJ}

Esta parte teórica do trabalho tentará esclarecer a partir do que e de onde foi pensada a metodologia da escola, e como se dá sua aplicação pelo menos teoricamente até o momento na conformação disciplinar. Perceba-se que a metodologia é um recorte de várias vertentes, seja a pedagogia soviética, seja a pedagogia de projetos.

Maciel (2014, p. 113) nos diz que em sua análise dos trabalhos mais significativos do IPUFRJ, entre professores e os idealizadores da proposta, que três fundamentos teóricos são convergentes a respeito da prática pedagógica até agora realizada na escola: o Trabalho como princípio educativo, a Politecnia e Pedagogia de Projetos. 


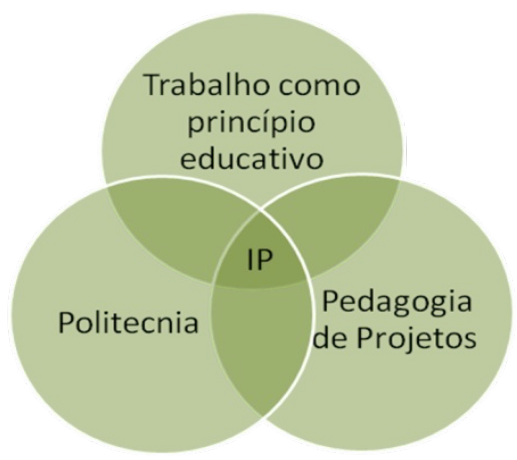

Figura 2: Os três fundamentos teóricos do Instituto Politécnico.

Um dos objetivos dessa metodologia é a formação integral dos estudantes, formação que supere a dualidade entre cultura geral e cultura técnica, que ao longo dos anos e da história tem se justificado como diferenças de formação para as classes média-alta e alta e a para os filhos da classe trabalhadora dentro do sistema capitalista. Portanto, segundo Frigotto (2006, p. 43), a formação integral do ser humano perpassa a superação da dualidade educacional que sintetiza a dualidade de classes, ou seja, uma necessidade conjuntural - social e histórica - para os filhos da classe trabalhadora.

Acompanhado deste princípio, que se diz ontológico, o método empregado de trabalho para formação é o que podemos resumir como "método politécnico", baseado na "politecnia". Segundo o Projeto Político Pedagógico - PPP, da escola:

\begin{abstract}
Tendo a educação politécnica como princípio, o IPUFRJ se posiciona de forma crítica ao modo de produção hegemônico, porém é consciente das condições estruturais vigentes. Cientes das contradições inerentes a essa relação, acreditamos que o processo educativo da classe trabalhadora passa pela tentativa de apropriação do conhecimento racional, enquanto meio de produção, como forma de superar a divisão social do trabalho e as relações de dominação hoje existentes. (IPUFRJ, PPP, p.1, 2011)
\end{abstract}

Maciel (2014, p.87), conclui que esta passagem do documento explicita a educação politécnica em seu viés socialista, na apropriação da ciência por parte dos sujeitos numa relação indissociável do trabalho manual com o intelectual, não sobrepondo um ao outro, além de uma educação crítica e contra hegemônica ao modo de produção capitalista. "Neste sentido, uma educação politécnica que seja contrária a este status quo só pode ser de base socialista" diz o autor. Segundo ainda Maciel, a superação da divisão social do trabalho é construção de viés marcante da literatura socialista. 
De modo mais prático e simplificado à questão educacional, a superação da dualidade já referida acima se transpõe dando unidade ao trabalho intelectual e manual, tendo por princípio a materialidade da realidade para a transformação social. Nisto se constituiria a politecnia.

Saviani (2003) reitera que a fragmentação do trabalho manual para os trabalhadores braçais, e o trabalho intelectual ou, de controle dos processos, para os donos dos processos produtivos, reproduz o que podemos chamar de divisão social do trabalho historicamente desenvolvido ao longo do capitalismo industrial. Essa mesma divisão se aplicaria ao ensino profissionalizante, na domesticação dos trabalhadores através de conhecimentos parcelados para atuação no mercado de trabalho.

Portanto, a formação integral também se relaciona com a crítica e reflexão para superar a fragmentação dos conhecimentos disciplinares, da educação geral e específica, do técnico e do político, do cidadão e do trabalhador, do manual e intelectual, da teoria e da prática. Segundo o pressuposto dessa concepção não haveria trabalho manual puro nem trabalho intelectual puro, todo trabalho seria integral dada a origem do entendimento da realidade humana constituída pelo trabalho (SAVIANI, 2003). O trabalho em sua concepção prática e material, desse modo, seria a essência primeira para a formulação do conhecimento, não destituído da análise, da síntese e da sistematização no plano intelectual.

Durante os anos de existência da escola, algumas escolhas foram feitas de modo a instituir determinadas características na construção do processo educativo (MACIEL, 2014), principalmente no sentido de não repetir as incongruências disciplinares e sim favorecer os intercâmbios e complementaridade dos saberes. Dessa forma, a adoção por campos de conhecimento, em vez de disciplinas, ganhou forma no IPUFRJ em cinco campos, a saber:

- PCSA - Práticas de Comunicação Social e Arte, composta por Língua estrangeira, Literatura, Língua Portuguesa, Artes e História Cultural;

- PDTA - Práticas Desportivas Aquáticas e Terrestres, composta por Educação Física, Dança e Teatro;

- CA - Ciências Ambientais, composta por Biologia, Geografia, Química e Física;

- RS - Relações Sociais, composta por História, Geografia, Filosofia, Sociologia e Antropologia; 
- CNTEC - Construção Naval e Outras Tecnologias, composta por Matemática, Física, Química e Construção Naval.

Os campos na prática funcionam de modo a colocar alguma organização aos docentes referente suas áreas de origem e especialidades, mas não limitam suas intersecções. É extremamente estimulada a autonomia dos docentes para que saiam de suas áreas de conforto e se arrisquem na interlocução com outros saberes, propiciando o estudo e o desvendamento da multidisciplinaridade. A utilização de disciplinas neste artigo é usada apenas sob efeito de explicação. No cotidiano escolar o conhecimento disciplinar é dificilmente utilizado.

Estes campos do conhecimento têm se mostrado a melhor forma de se trabalhar na escola através da integração dos saberes e superação das divisões mecanicistas impostas pelo desenvolvimento da ciência e tecnologia. Assim, o conhecimento é disposto livremente para atividades práticas e aplicado a partir da compatibilidade que se tenha com as atividades do Projeto Pedagógico em execução, sendo estimulado ao estudante o desenvolvimento de suas habilidades. Isto será ilustrado em tópico posterior quando se versar sobre o relato de experiência.

A terceira fundamentação do IPUFRJ refere-se a como articular os campos de conhecimento, qual seja, a Pedagogia de Projetos. Vazzi (2009 pg. 3) diz que o conceito de Pedagogia de Projeto baseia-se na construção de ambientes dinâmicos de aprendizagem que também é a base da teoria sócio-interacionista de Vigotsky, apontando a cooperação como fator destacado para a promoção da aprendizagem. Entende-se, portanto, a pedagogia por projetos como ferramenta de maximização do ensino/aprendizagem.

Nas referências de estudo do IPUFRJ cita-se a base pragmática de educação do liberal estadunidense John Dewey como um precursor do método, mas de modo restrito e pragmático ao uso da Pedagogia de Projetos. A respeito disso Maciel (2014, p. 107) analisa que este método apropriado pelo IPUFRJ é baseado em desafios, que fazem o estudante buscar meios de superá-lo, nisto tendo que pesquisar conceitos e assim fazer as apropriações necessárias.

O método de projetos proporciona ao educando partir de suas necessidades e problemáticas para gerar seu próprio conhecimento e aprendizagem pelo trabalho. Junte-se ao método as contribuições da pedagogia da atividade do soviético 
Revista Tecnologia e Sociedade, Curitiba, v. 11, n. 22, 2015

Edição Especial XII Encontro Nacional de Engenharia e Desenvolvimento Social

ISSN (versão online): 1984-3526

ISSN (versão impressa): 1809-0044

Vygotsky que poderiam ser opostas, mas interagem bem a partir da teoria da atividade e ação concreta, a materialidade, na resolução dos problemas da realidade do aluno, segundo também frisa Bemvindo et al. (2013, p. 17).

Dito isto, segundo pesquisa de Ventin $(2014$, p. 35) a pedagogia da atividade, que tem seu germe em Leontiev e Vygotsky, inspira as atividades norteadoras do Projeto, partindo-se das necessidades do aprendizado, do objeto material e da ação propriamente dita, que dará a concretude da atividade.

Outro aspecto do ensino-aprendizagem do IPUFRJ apoia-se no método tutorial, que consiste no acompanhamento de um número determinado dos estudantes durante o ano inteiro, afim de acompanhamento de seu aprendizado, dúvidas, reflexões, etc.

Essas são algumas das bases teórico-metodológicas e orientações que desde o início são estimuladas em sua compreensão por parte dos professores do IPUFRJ, principalmente através das discussões e leituras textuais com acompanhamento dos coordenadores do projeto no Curso de Formação e Qualificação em Residência Docente pelo qual os professores do Instituto passam no primeiro ano na Instituição. O curso teoricamente tem duração de dois anos, sendo o primeiro de imersão em sala de aula e aprendizado teórico, e o segundo de aperfeiçoamento em sala de aula e pesquisa educacional, que deve ser entregue ao final da qualificação.

Não obstante, o IPUFRJ por se tratar de um Projeto de Extensão, e, portanto, um laboratório de educação, onde se estimula a pesquisa, tem se consolidado dentro dessas bases com abertura suficiente para novas convergências teóricas que somem à experiência educacional realizada até o momento, desde que respeitados seus princípios pedagógicos e ideológicos.

Cabe aqui uma pergunta que esse artigo tentará responder a partir da perspectiva como Residente Docente após o primeiro ano de experiência na escola. A partir das bases teórico-metodológicas elencadas acima como orientadoras, como se deu a experiência em sala de aula na perspectiva do autor/professor?

\section{PRÁTICA EM RESIDÊNCIA DOCENTE NO IPUFRJ}

Antes do relato de experiência prática vivido em 2014, cabe esclarecer que o Instituto Politécnico atualmente conta somente com as séries do Ensino Médio e Técnico. Os cursos dividem-se em três formações integrais com os turnos de aula 
Revista Tecnologia e Sociedade, Curitiba, v. 11, n. 22, 2015

Edição Especial XII Encontro Nacional de Engenharia e Desenvolvimento Social

ISSN (versão online): 1984-3526

ISSN (versão impressa): 1809-0044

matutinos do ensino médio, são eles: curso de Cultura Marítima, de Audiovisual e Análises Químicas. A escolha das formações se dá após o término do $1^{\circ}$ ano do ensino médio, sendo esta série de preparação e onde se pôde ter a experiência em 2014 como docente da área de Ciências Ambientais - CA.

Antes de o ano letivo começar, as equipes, já formadas pela coordenação, de acordo com os campos do conhecimento, reúnem-se para formalizar os Projetos Pedagógicos. É um momento de amplos debates entre os professores onde deverá se consolidar de modo escrito todo o trajeto do ano em acordo com as capacidades e competências da equipe em questão e as experiências bem sucedidas que se possam repetir pedagogicamente. Ou seja, a ideia é que os projetos sejam sempre diferentes de ano para ano, podendo-se repetir os temas geradores, que são grandes questões geradoras de debate e pesquisa na produção de conhecimento nos projetos, seja pelos professores, seja pelos alunos.

O projeto da equipe de professores do $1^{\circ}$ ano em 2014 intitulou-se "Engenho e Arte" e teve como base as experiências anteriores com pescadores artesanais da região de Cabo Frio, bem como o trabalho com os cientistas da história moderna ocidental. Como equacionar esses temas geradores em apenas um ano e em um novo projeto não foi tarefa simples. O tema dado foi a análise crítica sobre o processo de produção do conhecimento e narrativas.

Abaixo segue o objetivo geral do projeto:

\begin{abstract}
Proporcionar aos alunos do $1^{\circ}$ ano do ensino médio a vivência dos cursos técnicos oferecidos pelo IPUFRJ (Cultura Marítima, Áudio e Vídeo, e Análises Químicas), através de um trabalho de pesquisa e extensão junto às comunidades pesqueiras de Cabo Frio e Arraial do Cabo, tendo como eixo condutor do projeto o processo de construção de narrativas (literatura, artes plásticas, teatro, música), assim como uma profunda reflexão sobre como o conhecimento e os diferentes saberes são construídos e apropriados ao longo da história da humanidade, de modo a lançar um olhar crítico sobre o processo de apropriação da ciência moderna pela burguesia, em contra ponto aos demais saberes historicamente marginalizados, excluídos e expropriados (Projeto Engenho e Arte, Ensino Médio, $1^{\circ}$ ano, 2014).
\end{abstract}

Além desse objetivo, na formalização do projeto tem-se uma breve descrição das etapas (3) e os objetivos específicos das mesmas, bem como os métodos a serem perseguidos para execução, já definidos desde o início do ano. Por conta de nesta série ainda não termos o curso técnico, o produto não foi planejado com um fim em si mesmo, dando-se aos alunos uma noção geral do que seriam os cursos técnicos posteriores a esta série. Trataram-se inicialmente de muitas reflexões, 
Revista Tecnologia e Sociedade, Curitiba, v. 11, n. 22, 2015

Edição Especial XII Encontro Nacional de Engenharia e Desenvolvimento Social

ISSN (versão online): 1984-3526

ISSN (versão impressa): 1809-0044

formação e leituras para a construção da narrativa própria do aluno como construção crítica do seu próprio conhecimento. Não foi objetivo deste projeto ter uma estratégia de intervenção na realidade, a ser trabalhada nos cursos técnicos posteriores, mas sim estimular uma visão crítica dos estudantes acerca dos saberes marginalizados, excluídos e expropriados.

Vale dizer que iniciar o projeto como professor numa escola como essa traz muita insegurança, apesar de qualquer leitura prévia que se tenha ou curso de formação na politecnia. Lida-se com uma metodologia diferente de tudo que se internaliza na formação convencional, sendo nesta última onde se realizam aulas sempre expositivas e uma organização diferente do tempo de trabalho. A insegurança e as contradições são inerentes ao aprendizado dos docentes numa primeira fase, sendo adquirida com o tempo uma maior segurança a partir do apoio nas questões materiais. Pode-se dizer nesse sentido que a liberdade do método precisa ser apreendida pelos novos docentes, e isto leva tempo.

Ressalte-se então que o maior aprendizado que se pôde ter durante o ano adveio da experiência dos professores mais antigos que estão a pelo menos cinco anos no IP acumulando acertos e erros e experimentando estratégias de atividades. Lembre-se que a inauguração dessa escola é recente, de 2008. Abaixo irá se explorar cada etapa do projeto, tentando apresentar as estratégias adotadas pela equipe e o que de mais significativo foi presenciado.

Primeira etapa - Pesquisou e refletiu sobre o que seria ciência na História Antiga. O início dessa etapa, após apresentação geral do projeto para os estudantes do $1^{\circ}$ ano, foi apresentar-lhes através da leitura de mitos, gregos ou romanos, o que aquelas histórias narravam para a época e por que daquele modo se constituíam, assim elas explicavam quais fenômenos naturais? Ou melhor, do que aquela Narrativa dava conta? Para isso houve aprofundamento nos primeiros filósofos naturais que buscavam explicar o mundo de coisas sem a negação dos deuses. Começou-se pelo poeta antigo Lucrécio através da obra "Sobre a Natureza das Coisas", depois pelas Escolas Filosóficas e os modelos astronômicos, até chegar ao "Mito da Caverna" de Platão.

Uma das atividades realizadas com os educandos foi a identificação de fenômenos físicos da natureza e interpretação através de criação de uma narrativa mitológica. Desse modo, tentou-se mostrar a importância dessa forma de ver o 
mundo, e não simplesmente ignorá-la ou inferiorizá-la, tentando mostrar que não somente os gregos e romanos explicavam o mundo através dos mitos, mas muitos outros povos e culturas, os quais foram objetos de pesquisa em sala. A utilização do poeta Lucrécio na explicação dos fenômenos trouxe uma conexão com a racionalidade do mundo atual e inclusive cumplicidade na geração do conhecimento entre a obra do filósofo e os jovens. Já a leitura de Platão mostrou-se muito difícil num primeiro momento, mas depois se estimulou a criação de imagens que ilustrassem o acontecimento e debates coletivos através de Arenas, trazendo assim maior compreensão da mensagem filosófica.

As Arenas foram momentos instituídos nos projetos do primeiro ano para debates coletivos, onde os estudantes ficam frente a frente ao redor da sala de aula, como num Teatro de Arena da década de 1960 no Brasil. Este formato estabelece que o saber seja gerado entre os educandos de modo coletivo e os próprios se vejam cara a cara, ao invés de um 'palco' estabelecido pelo professor no método tradicional, onde só o mesmo é instituído de saber.

Nesses momentos houve a oportunidade do estabelecimento do conflito dos conteúdos adquiridos no projeto nesta primeira etapa e seu questionamento ou contradição na geração do saber coletivo. Entenda-se que há um movimento contraditório por natureza e ao mesmo tempo proposital do projeto entre os conhecimentos transmitidos através de conteúdos da educação convencional por um lado, e por outro, o que se fazer com este conteúdo nos momentos de debate na consolidação pela turma de seus saberes coletivos.

Este movimento pode ser visto também como uma estratégia dos próprios docentes na consecução do projeto, com todas as contradições da vida real e que muitas vezes não se tem respostas imediatas. Ou seja, a contradição não é somente dos docentes, mas deve ser percebida também pelos educandos.

Segunda etapa - Pesquisou, refletiu e apresentou uma narrativa sobre o contexto pré e pós-revolução científica e sobre os processos de produção do conhecimento relativo aos principais conceitos da ciência a partir de uma visão eurocêntrica, onde contextualmente nasce a Ciência Moderna. Esta etapa foi a mais duradoura no projeto, ocupando o segundo e o terceiro bimestre praticamente inteiro. 
Também foi uma etapa densa em termos de esclarecimento da filosofia e ciência do mundo ocidental em que se fez leituras de Marilena Chauí - "Convite a Filosofia", Leo Huberman - "História da Riqueza do Homem", que tratou um pouco do período médio da história e a derrocada do Feudalismo na Europa; e Luís Vaz de Camões - "Os Lusíadas" em resgate ao movimento renascentista. O período renascentista foi retratado também pela obra teatral de Bertold Brecht - "A vida de Galileu", em que se pode contextualizar o período histórico e as discussões geocêntricas de poder do catolicismo, e heliocêntricas, de uma nova classe urgindo.

O período médio da história foi polemizado se realmente era um período de trevas, de escuridão para o mundo, ou se ao contrário, ocorreu desse modo apenas para a história ocidental do mundo. Atividades de CNTec tentaram trazer essas reflexões através da história das invenções, mostrando que muitos inventos e descobertas tais quais o vidro, as lentes, as embarcações, etc., há séculos já haviam sido descobertos por culturas e povos do mundo oriental e indígena. Essas pesquisas tiraram o foco dos educandos do conhecimento pertencente ao mundo Ocidental Moderno.

$\mathrm{Na}$ atividade com Brecht pôde-se fazer um trabalho muito interessante que misturou uma abordagem sobre História da Ciência, contextualizando o período de descobertas de Galileu, precedente a Newton, nos estudos gravitacionais, bem como a inauguração de um novo Paradigma. O Teatro também foi utilizado na encenação de um trecho da peça através dos métodos do Teatro de Augusto Boal, de concepção materialista, de utilização e desmecanização de movimentos. Aqui se pôde ter claramente a comprovação de que os trabalhos ditos manuais, ou corporais, práticos, ou a partir da matéria, tem um valor imediato para o aprendizado, trazendo interações coletivas importantes na inserção dos elementos de análise ou do trabalho intelectual.

Ressalte-se a riqueza deste avanço de etapa no projeto, uma vez que se pôde perceber claramente também que os conhecimentos estimulados durante o projeto não são apropriados através de decoração, mas, nesta escola, fundamentalmente na criação das relações necessárias entre os conhecimentos, no caso, da primeira e segunda etapa até então. A grande frustração como professor era perceber que muitas vezes o educando não percebia a riqueza daquelas relações no processo educativo imediatamente. $O$ que foi acontecer somente no 
Revista Tecnologia e Sociedade, Curitiba, v. 11, n. 22, 2015

Edição Especial XII Encontro Nacional de Engenharia e Desenvolvimento Social

ISSN (versão online): 1984-3526

ISSN (versão impressa): 1809-0044

final do Projeto, quando os saberes adentraram de modo prático nas pesquisas de campo.

Esta frustração teve a ver também com a falta de domínio do método. Nesses momentos, o professor normalmente recorre ao método convencional de ensino quando não encontra solução prática, consequentemente trabalha de modo expositivo e em excesso os conteúdos. Esquece-se das dimensões essenciais desse conteúdo para se acessar o conhecimento, no tempo necessário para estabelecimento das relações necessárias e boa compreensão por parte do estudante. Assim, mais valem as dimensões essenciais do conhecimento, que propiciem a autonomia do educando para o trabalho, a uma enxurrada de conteúdo que o deixe atônito e desestimulado, sem ponto de partida.

Nesse sentido, Vazzi (2012, p. 4) diz que o conhecimento não é "passado" ou transmitido de uma pessoa para outra, mas deve ser construído através da atuação do próprio indivíduo sobre o que deve ser conhecido. Diz ainda que, essa atuação consiste em explorar, observar, comparar, pesquisar, relacionar, discriminar, levantar hipóteses, concluir, e por fim, posicionar-se.

A individualidade nesse processo é fundamental, uma vez que cada estudante teria seu tempo de aprendizado. Todavia, num projeto pedagógico o aprendizado individual pode ser potencializado entre jovens, se estes tomarem para si o projeto. Isto aconteceu neste projeto nos momentos de Arena em que a turma discordou do direcionamento dado ao projeto pelos professores em determinado momento. Isto fez o grupo de professores se reposicionar e reconhecer falhas no planejamento, que a própria turma soube detectar.

Voltando a etapa, para sintetizar os avanços dos conhecimentos do projeto uma das estratégias dos professores foi orientar a construção de uma Linha do Tempo pelos grupos de trabalho, de acordo com as anotações dos educandos. O intuito dessa orientação era sugerir que a expressão "Linha do Tempo" se mostrava inapropriada. Nesse sentido, deram-se outros subsídios como mapas mentais, teias do conhecimento, redes, etc. A resposta mais interessante foi a de um grupo que sintetizou tudo até ali apreendido numa Árvore do Conhecimento, representando o Projeto, fazendo analogias com crescimento do conhecimento, ramificação, frutificação, decomposição, que em atividade acabou sendo muito aceita entre os 
Revista Tecnologia e Sociedade, Curitiba, v. 11, n. 22, 2015

Edição Especial XII Encontro Nacional de Engenharia e Desenvolvimento Social

ISSN (versão online): 1984-3526

ISSN (versão impressa): 1809-0044

próprios colegas de turma, trazendo um senso ecológico implícito à atividade e ao conhecimento.

Esta última atividade tentou sugerir aos aprendizes também a inapropriada forma como a Ciência é concebida através de acúmulos de conhecimento (KUHN, 1962), evolução e linearidade. Nesse sentido, no trabalho com os cientistas, podese, demonstrar novamente com a abordagem da História da Ciência que muitos cientistas também se equivocaram na compreensão dos fenômenos, como na Teoria de Flogisto na explicação da Combustão.

A Ciência Moderna, o conhecimento gerado no século XVIII e a Tecnologia dela proveniente não deixaram de ser retratados como um grande empreendimento moderno, como base material incorporando-se ao trabalho produtivo para os donos dos meios de produção servirem-se, apropriarem-se e dominarem os trabalhadores.

Esta etapa encerrou-se com a proposição de atividades através de uma feiracientífica para a turma buscando o aprofundamento dos fenômenos físicos e químicos através de expoentes cientistas. A feira foi mais uma vez exposta no Conselho do $3^{\circ}$ bimestre para os pais dos estudantes.

Em tempo, uma das abordagens complementares a ser utilizadas no IP e que interagem perfeitamente com as bases teórico-metodológicas da escola e a formação integral do estudante diz respeito aos estudos em Ciência, Tecnologia e Sociedade - CTS, em relação a maior inserção e participação social nos assuntos envolvendo ciência e tecnologia, o que ainda não se explorou nos projetos.

Esta abordagem baseia-se no questionamento da concepção unidirecional e determinista da tecnologia na relação entre tecnologia e sociedade, de modo que o desenvolvimento social tem sido, em seus aspectos econômicos, políticos e culturais, uma consequência direta e linear do desenvolvimento tecnológico pura e simplesmente. De acordo com Corrêa et al. (2013, p.8), é importante que os estudos em CTS abram-se aos temas educacionais e vê na educação politécnica terreno fértil para problematização de questões tecnocientíficas de maneira crítica, participativa e colaborativa em sala de aula.

Araújo et al. (2012, p. 108) também vê integrações entre as categorias CTS e Educação e Trabalho, visto que ambas são contrárias ao estreitamento da formação e visam associar formação ao exercício da cidadania no Ensino Profissional e Técnico. Segundo o autor, parece razoável admitir-se a possibilidade de um 
Revista Tecnologia e Sociedade, Curitiba, v. 11, n. 22, 2015

Edição Especial XII Encontro Nacional de Engenharia e Desenvolvimento Social

ISSN (versão online): 1984-3526

ISSN (versão impressa): 1809-0044

currículo estruturado tendo os dois eixos, para isso define objetivos curriculares para a articulação conceitual, desde que sejam entendidos interdisciplinarmente.

Terceira etapa - Pesquisou e refletiu sobre os saberes historicamente marginalizados, excluídos e expropriados, a partir do estudo das comunidades pesqueiras da região de Cabo Frio e Arraial do Cabo.

Essa etapa denotou grande oportunidade de aprendizado e de compreensão do projeto de modo geral para os estudantes, uma vez que puderam se deparar no campo com a prática dos saberes historicamente construídos empiricamente, e contrariar o senso comum que diz que a única narrativa detentora de racionalidade e verdade é a científica.

Puderam realizar através das entrevistas qualitativas um Resgate Cultural de saberes que têm sido marginalizados, excluídos e expropriados pelo poder hegemônico. Atividades de pesquisa em campo foram essenciais para essa percepção, indo nas áreas de desembarque do pescado, percebendo as diferenças de infraestrutura dada aos pescadores e aos turistas, nas áreas de turismo. Houve percepção também conversando com os pescadores em campo para saber sobre a vida deles e deparando-se surpreendentemente com saberes sistêmicos sobre a vida no mar e do mar, que até então não eram esperados, seja por uma falta de conhecimento ou mesmo preconceito por parte dos estudantes, que os viam sem valor algum para a ciência e para a região de Cabo Frio.

Outras falas importantes foram a dos pescadores denunciando as faltas do poder público para com a classe, as condições precárias de vida e do trabalho, a concorrência desleal com outros setores como o turismo de massa e a pesca industrial, além, claro, de toda a simplicidade dos pescadores em contar todo tipo de aventuras tidas no mar, o que conquistou a atenção geral dos estudantes. Este momento prático do projeto foi fundamental para a concretização de todos aqueles conhecimentos e relações entre conceitos e saberes estimulados desde o início nos estudantes. Finalmente a parte eminentemente prática do projeto veio sedimentar o arcabouço teórico durante o ano, principalmente daqueles estudantes que fizeram durante o projeto bons registros e produções textuais das atividades.

Infelizmente esta etapa não superou o denuncismo da situação criticada em relação aos pescadores de Arraial do Cabo e Cabo Frio, por conta da complexidade do problema, pela falta de um plano de ação e apoios institucionais. É importante 
Revista Tecnologia e Sociedade, Curitiba, v. 11, n. 22, 2015

Edição Especial XII Encontro Nacional de Engenharia e Desenvolvimento Social

ISSN (versão online): 1984-3526

ISSN (versão impressa): 1809-0044

dizer que o IPUFRJ é uma escola com inúmeros problemas de infraestrutura, reconhecimento institucional e sobrevive à margem dos recursos orçamentários da educação, como a maioria das outras escolas. Não à toa, existe um sentimento de resistência para que a escola, os pais, os estudantes e principalmente os residentes docentes não abandonem a experiência, que tem se mantido por causas eminentemente políticas nesse cenário.

Outro ponto a se enfatizar é o Resgate Cultural oportunizado neste trabalho com os pescadores artesanais, que teve, nesse sentido, uma motivação muito especial, uma vez que se pôde entender finalmente do que se tratava um conceito muito trabalhado nesse e noutros projetos: a Narrativa de Resistência. Esse conceito foi fazer sentido somente no final, quando se fez um paralelo entre as dificuldades de sobrevivência do pescador em sua atividade e o professor no nosso modelo educativo no IP, resistindo à margem da educação convencional no Brasil. Isso trouxe um sentido de compreensão para os alunos desse projeto incrível a ponto de passarem a valorizar muito mais o IPUFRJ e nossas atividades, tornando a escola viva, no melhor sentido da palavra.

Todo esse trabalho, por fim, foi finalizado com a apresentação de cinco produtos finais, de acordo com os grupos de trabalho. A partir das histórias e entrevistas coletadas em campo, o desafio dos alunos passou a ser a Transposição da Linguagem, ou seja, transpor os conhecimentos adquiridos para outras linguagens artísticas, seja para a Música e Literatura, Audiovisual, Xilogravura, Dança e Expressão Corporal e Cultura Marítima. Os resultados produzidos, apesar do pouco tempo de trabalho, mostraram ótima qualidade e compreensão por parte dos estudantes.

No grupo de Música e Literatura, inspirados nas construções dos versos de "Os Lusíadas", foram feitas seis composições musicadas sobre os saberes apreendidos em campo, de acordo com os conhecimentos de música do orientador e os conhecimentos prévios dos estudantes. O grupo de Audiovisual propôs-se a fazer duas produções em linguagem audiovisual, um que construiu uma narrativa da história e problematizações com os pescadores através de imagens e entrevistas; e outro de registro do Projeto. Ambos os vídeos ficam para o acervo da escola e são exibidos sempre para as turmas posteriores. O grupo de Xilogravura transpôs todas as histórias de pescadores, adquiridas em entrevistas de campo, através da 
linguagem xilográfica, em composição de harmonia do desenho e da técnica. $O$ grupo de Dança e Expressão Corporal utilizou-se da dança contemporânea, inspirados em Pina Bausch - coreógrafa, dançarina e pedagoga alemã, para retratar os movimentos dos pescadores e da natureza, criando uma coreografia ao som de tambores. Por fim, o grupo de Cultura Marítima teve como foco a pesquisa dos princípios físicos das embarcações artesanais e fez uma apresentação ao fim da etapa, organizando uma espécie de arena mostrando suas conclusões.

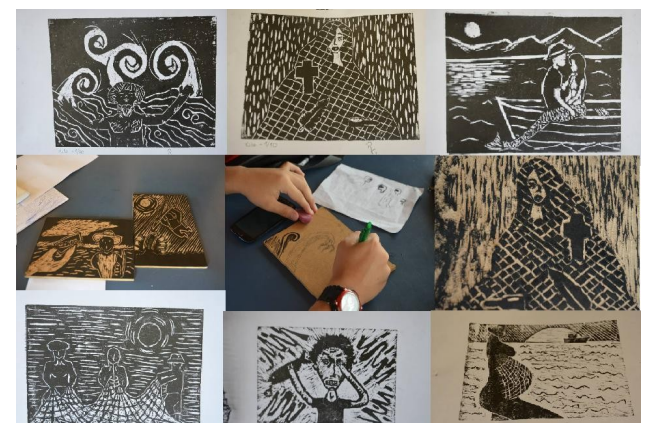

Figura 3: Fotos de xilogravuras apresentadas pelos estudantes do IPUFRJ. Fonte: Júllia Turrini.

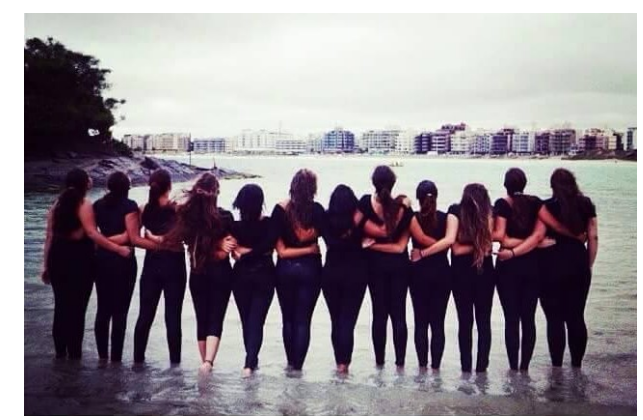

Figura 4: Grupo de dança fazendo apresentação final na praia do Forte, Cabo Frio - RJ. Fonte: Júllia Turrini.

Esta transposição dos saberes apreendidos em campo para uma linguagem artística, retraduzindo o que foi em campo pesquisado, foi inspiradora para os trabalhos finais, visto que foi uma criação própria dos estudantes para eles mesmos. O trabalho possibilitou a integração de tudo que já havia sido visto durante o projeto e trouxe existência prática para o título Engenho e Arte.

Entre outras percepções apreendidas durante o ano que só o processo de trabalho final do projeto deixou muito claro, destaco nesse modelo educacional a oportunidade de autonomia que os alunos podem desenvolver no decorrer do tempo pelo fato de manipular os conhecimentos na resolução de problemas. A desenvoltura na resolução dos problemas que surgem no processo de trabalho é 
obrigação do aluno que busque sua formação humana, integral e queira amadurecer, diante quaisquer dificuldades encontradas, sejam materiais ou de orientação pedagógica. Principalmente por esta escola estar em vias de construção e ser experimental, informação que é compartilhada com os estudantes a todo o momento.

Nesta etapa final do projeto pôde-se perceber isto através de três momentos. O grupo de música não contava com todos os instrumentos ou boa acústica para gravação dos áudios após as composições. Improvisaram-se alguns instrumentos e a locação para gravação na escola, dentro de um contêiner. Somente depois é que reuniram contribuição para pagamento de um estúdio com boa acústica fora da escola. No grupo de Dança, os estudantes não contavam com orientação suficiente dos professores para o trabalho por conta das deficiências de formação docente na área, mas um aluno entendia mais de dança que os demais e buscou orientar o processo, numa construção coletiva que os fez valorizar o esforço individual e coletivo. O grupo de audiovisual, também teve problemas com material e orientações, mas conseguiu superar as adversidades de modo a entender que os erros cometidos durante o processo foram fundamentais para compreenderem a importância da organização do trabalho em etapas para o produto final. Essas e outras conclusões foram todas tiradas da produção textual dos educandos no relatório final, que chamamos de Diário de Bordo nessa última fase. Abaixo trecho original e transcrito de Diário de uma estudante do IPUFRJ.

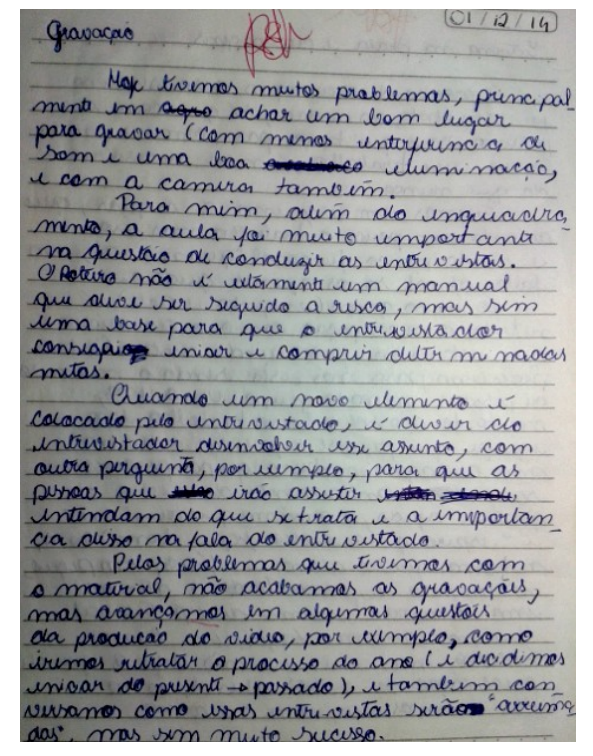

Figura 5: Diário de Bordo de estudante do grupo de audiovisual relatando suas dificuldades e aprendizado com entrevistas. 
Revista Tecnologia e Sociedade, Curitiba, v. 11, n. 22, 2015

Edição Especial XII Encontro Nacional de Engenharia e Desenvolvimento Social

ISSN (versão online): 1984-3526

ISSN (versão impressa): 1809-0044

\begin{abstract}
"Hoje tivemos muitos problemas, principalmente em achar um bom lugar para gravar (com menos interferência de som e uma boa iluminação e com a câmera também).

Para mim, além do enquadramento, a aula foi muito importante na questão de conduzir as entrevistas. O roteiro não é exatamente um manual que deve ser seguido a risca, mas sim uma base para que o entrevistador consiga iniciar e cumprir determinadas metas.

Quando um elemento é colocado pelo entrevistado, é dever do entrevistador desenvolver esse assunto, com outra pergunta, por exemplo, para que as pessoas, que irão assistir entendam do que se trata e a importância disso na fala do entrevistado.

Pelos problemas que tivemos com o material, não acabamos as gravações, mas avançamos em algumas questões da produção do vídeo, por exemplo, como iremos retratar o processo do ano (e decidimos iniciar do presente $\rightarrow$ passado), e também conversamos como essas entrevistas serão 'arrumadas', mas sem muito sucesso".
\end{abstract}

Em atividade prática de entrevista na escola para o grupo de audiovisual, a estudante acima apreende com algumas orientações dadas e desenvolve texto de diário em que sintetiza seu processo de aprendizado, além da estratégia de autonomia frente às deficiências materiais que impediam o desenvolvimento da atividade naquele momento do projeto.

Outro ponto relevante é a função do professor nesse modelo educativo, que passa a ser planejador de atividades e orientador das necessidades individuais que cada educando apresentar ou necessidades coletivas. A palavra professor em muitos momentos acaba por se tornar antiquada, se levarmos em conta aquela figura do professor como único detentor dos conhecimentos. As atividades podem ter desdobramentos imprevistos dependendo da turma. Muitas vezes me senti como facilitador do processo de aprendizagem dos alunos, seja dentro dos meus conhecimentos específicos de formação universitária, seja em áreas que precisei me aventurar um pouco mais, como o teatro.

A esse respeito, Paulo Freire em "Pedagogia da Autonomia" faz uma referência muito parecida ao docente deixando de ser transmissor de conteúdos acríticos. Abaixo seguem dois depoimentos de estudantes do IPUFRJ a respeito do papel do professor nessa escola.

Mesmo que um dos principais pontos da metodologia da escola seja criar pessoas autônomas, e que esse objetivo seja alcançado várias vezes, o estudante ainda precisa de auxílio na hora de aprender e apresentar seus resultados. De certa forma, acho que essa seja a grande diferença entre esses professores do IPUFRJ e os de escolas tradicionais. Nelas, os professores apenas expõem os conteúdos, já no IPUFRJ, eles acabam interagindo com os alunos e tentando fazê-los pensar ao máximo para assim conseguirem obter os conhecimentos. E esse é um dos grandes 
Revista Tecnologia e Sociedade, Curitiba, v. 11, n. 22, 2015

Edição Especial XII Encontro Nacional de Engenharia e Desenvolvimento Social

ISSN (versão online): 1984-3526

ISSN (versão impressa): 1809-0044

diferenciais da escola, a forma como os professores ensinam. (Depoimento da Estudante I, do IPUFRJ, mai. de 2015, grifo nosso).

(...) ser professor é ter uma missão de repassar conhecimentos e também receber. E é isso que o politécnico apresenta. É saber dar e também receber. (...) Ensinar politécnico não é transferir conhecimento, mas criar possibilidades para a nossa própria educação ou a nossa construção como cidadãos. É de extrema importância opor sua opinião, seu pensar e reconhecer na sociedade. (Depoimento da Estudante II, do IPUFRJ, mai. de 2015, grifo nosso).

Acima, os dois depoimentos coletados dão conta do já citado processo de facilitação do aprendizado e autonomia, mostrando que o estudante não é totalmente autônomo e carece de condução, seja através do projeto pedagógico, ou mesmo de mínimas instruções, de modo a criar possibilidades educativas, ou atividades, para que num momento posterior seja avaliado. Como já colocado, este processo oportuniza e credita ao estudante sua autonomia.

Pese-se que toda essa concepção, apesar de se mostrar libertadora e aparentemente mais eficaz como método de ensino-aprendizagem, está posta em outro tempo que não o da educação convencional que avalia quantitativamente e sem continuidades entre as séries. O trabalho como princípio educativo não é adotado como aparentemente se pode pensar, definido rigidamente através da eficiência do trabalhador e em horários estanques de entrada e saída nas fábricas, mas sim entretempos de lazer, atividades lúdicas e mesmo o ócio criativo que estimulam o trabalho. O que não significa que a disciplina e assiduidade sejam secundárias. Pelo contrário, sempre são levados em consideração nas avaliações individuais do estudante.

Sobre isso Maciel et al. (2012, p.9) diz que é o trabalho pedagógico como atividade criadora, onde os produtos são socialmente úteis - como a prancha de surfe feita em madeira de agave, planta exótica da região, pelo curso técnico de cultura marítima (BEMVINDO, V. et al., 2013). No entanto, esses produtos não têm fins comerciais nem estão num complexo produtivo mais amplo, pois são pedagógicos.

\section{CONSIDERAÇÕES FINAIS}

Esse trabalho teve a função de expor um relato de experiência após a exposição da questão metodológica que o cerca, proporcionando o debate entre 
Revista Tecnologia e Sociedade, Curitiba, v. 11, n. 22, 2015

Edição Especial XII Encontro Nacional de Engenharia e Desenvolvimento Social

ISSN (versão online): 1984-3526

ISSN (versão impressa): 1809-0044

teoria estudada e a prática vivida, além de levantar registro e dados qualitativos para posteriores análises. Devemos agora voltar à pergunta feita inicialmente: Como se deu a experiência em sala de aula na perspectiva do autor/professor?

Considera-se que as estratégias utilizadas nas atividades educacionais mostraram-se tão importantes quanto os preceitos metodológicos do IPUFRJ, no entanto, a descoberta e leitura pessoal que se pode fazer da metodologia do IP ainda é insipiente, sendo que está num campo muito mais racional e teórico que prático e vivencial. Ao final do primeiro ano de experiência na escola pude vivenciar inúmeras dificuldades de aprendizado próprias de quem veio de um sistema convencional de ensino adaptando-se a outro sistema em experimentação. Dentre as quais, lançar atividades educativas, em vez de ministrar o conhecimento de modo expositivo a todo o momento.

Pode-se dizer que poucos docentes na escola dominam com expertise e perfeição os preceitos teóricos e metodológicos, ou os fundamentos que justifiquem o modelo, apesar de repetirem incansavelmente algumas dessas ideias e conseguirem adotar um método que apresenta alguma eficiência em práticas de ensino/aprendizagem no IPUFRJ. Mas esse domínio teórico não parece fundamental atualmente, visto que teoricamente muito se tem em conteúdo e pesquisas de justificação teórica do modelo disponível em acervo ou na internet. Isso inclusive é extremamente ressaltado no curso de residência docente.

Percebo, de outro modo, que o principal motivador para a crítica e avanços teóricos futuros da própria escola seja o registro, desenvolvimento e esclarecimento das Atividades Pedagógicas a partir das bases orientadoras simples e essenciais de acesso e apropriação do conhecimento que deram e tem dado bons resultados no IPUFRJ. Visto que, recorrentemente o docente, em momentos de dificuldades em sala, volta-se para bases orientadoras convencionais do ensino.

De outro modo, infelizmente professores temporários passam pelo projeto e levam consigo seus saberes, boas práticas e experiências, sem nenhum registro, o que dificulta as confrontações com as teorias que fundamentam a escola. Esta sistematização dos registros pode dar um bom aporte de experiências práticas para acréscimo da teoria da pedagogia da atividade a partir do IPUFRJ, que aparenta ter sido pouco esmiuçada com apoio bibliográfico dos teóricos Leontiev e Vigotsky nas 
Revista Tecnologia e Sociedade, Curitiba, v. 11, n. 22, 2015

Edição Especial XII Encontro Nacional de Engenharia e Desenvolvimento Social

ISSN (versão online): 1984-3526

ISSN (versão impressa): 1809-0044

bibliografias consultadas para este trabalho, além de referências mais contemporâneas, que parecem em falta, segundo Asbahr (2005).

De modo prático, este relato de experiência também traz elementos de análise para além da metodologia. Esta, por enquanto, parece ser um meio, e não um fim. Os projetos do IP tem liberdade para construções que respeitem os princípios ideológicos da escola e seus preceitos, podendo caminhar por novos campos do conhecimento que a metodologia da escola muitas vezes limita-se. Isso acontece através da oportunidade de pesquisa dada aos Residentes Docentes e aplicação prática nos projetos pedagógicos.

Outro exemplo disso, neste artigo, é que a Ciência nesse projeto foi trabalhada ressaltando-se seu caráter não linear e não evolucionista, num contexto histórico de utilitarismo do saber científico pela classe dominante do sistema capitalista, onde geralmente a ciência é iluminada, caminha de maneira evolutiva, naturalizando-se dentro de uma perspectiva em que o trabalhador pouco consegue se apropriar ou resgatar conhecimentos. Este foi um ponto fora da reta, traçado nos preceitos metodológicos anteriormente mencionados no artigo, mais do que apropriar-se dos fundamentos científicos do trabalho. Com mais amadurecimento, isto poderia tornar-se um preceito metodológico da escola através do auxílio da abordagem CTS.

Em complementaridade ao projeto Engenho e Arte, nesse exemplo, os estudos CTS fariam sínteses mais produtivas educacionalmente nos cursos técnicos posteriores a esta série, fortalecendo ainda a proposta do fazer científico atrelado às utilidades sociais como princípio do IPUFRJ.

Por fim, este relato de prática docente em Trabalho \& Educação no Instituto Politécnico da UFRJ pretende ser um registro e uma reflexão das atividades ali realizadas. É a expectativa do autor contribuir para sua divulgação, análise crítica e melhoria desse projeto inovador.

\section{REFERÊNCIAS}

ASBAHR, F. S. F. A pesquisa sobre a atividade pedagógica: contribuições da teoria da atividade. Revista Brasileira da Educação. No 29. Maio/Jun/Jul/Ago, 2005. Disponível em: <www.scielo.br/pdf/rbedu/n29/n29a09>. Acesso em: 15 mai. 2015. 
Revista Tecnologia e Sociedade, Curitiba, v. 11, n. 22, 2015

Edição Especial XII Encontro Nacional de Engenharia e Desenvolvimento Social

ISSN (versão online): 1984-3526

ISSN (versão impressa): 1809-0044

AMORIM, F.; ALHO, A. T. P. Introdução à Engenharia Naval: Desafios e Realizações. In: Jorge Luiz Nascimento. (Org.). Educação em Engenharia - Metodologia. 1ed.São Paulo: Editora Mackenzie, 2002, v. , p. - .

ARAÚJO, A. B.; SILVA, M. A. da; Ciência, Tecnologia e Sociedade; Trabalho e Educação: possibilidades de integração no currículo da Educação Profissional Tecnológica. Belo Horizonte. V.14, n.1, p.99 - 112. Jan. - Abr. 2012. Disponível em: <http://www.portal.fae.ufmg.br/>. Acesso em: 28 dez. 2014.

BACHELARD, G. A Formação do Espírito Científico: Contribuição para uma psicanálise do conhecimento. Tradução de Estela dos Santos Abreu. Rio de Janeiro: Contraponto Editora, 1996.

BEMVINDO, V.; ALMEIDA, C.; TURRINI, J. Formação humana no Instituto Politécnico da UFRJ: o trabalho como princípio educativo a partir da pedagogia de projetos. Niterói: Trabalho Necessário/UFF, v.16, ano 11, n.16, 2013.

CORRÊA, R. F.; GEREMIAS, B. M.; Determinismo Tecnológico: elementos para debates em perspectiva educacional. Revista Tecnologia e Sociedade. Curitiba. N. 2, out. 2013. Disponível em: <http://files.dirppg.ct.utfpr.edu.br/ppgte/revistatecnologiaesociedade/rev_sumario_EdEspecia ITECSOC2013.html>. Acesso em: 28 dez. 2014.

FRIGOTTO, G; CIAVATTA, M; RAMOS, M; Concepção e experiências de ensino integrado. [S.1], Boletim MEC. n.7, p. 29-51, mai./jun. 2006. Disponível em: $<$ http://portal.mec.gov.br> Acesso em: 27 jan. 2014.

KUHN, T. S. A estrutura das revoluções científicas. 2. ed. São Paulo: Perspectiva, 1978

MACIEL, C. L. A. ; BEMVINDO, V. ; TURRINI, J. O trabalho como princípio educativo e a concepção de formação humana no instituto politécnico da universidade federal do rio de janeiro. in: Educação e Pedagogias: problematizações, 2012, Santa Cruz do Sul- RJ.

MACIEL, C. L. A. Educação integral em tempo integral: concepção e prática no Instituto Politécnico da Universidade Federal do Rio de Janeiro - Cabo Frio - RJ. 195 f. Dissertação (Mestrado em Educação) - Centro de Ciências Humanas e Sociais - CCH, Universidade Federal do Estado do Rio de Janeiro - UNIRIO, 2014.

MOURA, D. H.; GARCIA, S. R. O.; RAMOS, M. N.; Documento Base - Educação Profissional Técnica de Nível Médio. Integrada ao Ensino Médio. Brasília: Secretaria de Educação Profissional e Tecnológica - Ministério da Educação, 2007.

INSTITUTO POLITÉCNICO DA UFRJ - IPUFRJ. Projeto Político Pedagógico - PPP. Cabo Frio - RJ, 2011.

RODRIGUES, Chinthia. et al. Revista Carta na Escola. Em busca de um novo modelo. Publicado na edição 92, de novembro de 2014. Disponível em: <http://www.cartanaescola.com.br/single/show/460> Acesso em: 10 jan. 2015.

SAVIANI, Demerval. O choque teórico da politecnia. Trabalho, Educação e Saúde - v.1, n.1 (2002). Rio de Janeiro: Fundação Oswaldo Criz, Escola Politécnica de Saúde Joaquim Venâncio, 2003. 
Revista Tecnologia e Sociedade, Curitiba, v. 11, n. 22, 2015

Edição Especial XII Encontro Nacional de Engenharia e Desenvolvimento Social

ISSN (versão online): 1984-3526

ISSN (versão impressa): 1809-0044

VAZZI, Marcio R.G. A Pedagogia de Projetos e a construção do conhecimento científico. 2009. Trabalho apresentado como requisito de finalização da Disciplina Compreensão Pública da Ciência e Tecnologia. Disponível em: <www.vazzi.com.br $>$ Acesso em: 10 mai. 2015.

VENTIN, Marcella F. Instituto Politécnico da UFRJ: motivações, percepções e perspectivas de uma Escola Universitária baseada na Educação pelo Trabalho. 2014. 152 f. Dissertação (Mestrado em Educação) - Faculdade de Educação, Centro de Filosofia e Ciências Humanas, Universidade Federal do Rio de Janeiro, Rio de Janeiro, 2014. 